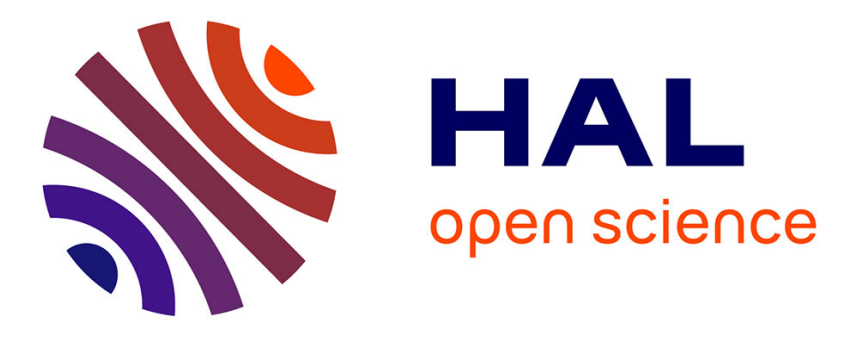

\title{
Towards Continuous Collaboration on Civic Tech Projects: Use Cases of a Goal Sharing System Based on Linked Open Data
}

Tadachika Ozono, Toramatsu Shintani, Shun Shiramatsu, Teemu Tossavainen

\section{- To cite this version:}

Tadachika Ozono, Toramatsu Shintani, Shun Shiramatsu, Teemu Tossavainen. Towards Continuous Collaboration on Civic Tech Projects: Use Cases of a Goal Sharing System Based on Linked Open Data. 7th International Conference on Electronic Participation (ePart), Aug 2015, Thessaloniki, Greece. pp.81-92, 10.1007/978-3-319-22500-5_7 . hal-01587631

\section{HAL Id: hal-01587631 \\ https://hal.inria.fr/hal-01587631}

Submitted on 14 Sep 2017

HAL is a multi-disciplinary open access archive for the deposit and dissemination of scientific research documents, whether they are published or not. The documents may come from teaching and research institutions in France or abroad, or from public or private research centers.
L'archive ouverte pluridisciplinaire HAL, est destinée au dépôt et à la diffusion de documents scientifiques de niveau recherche, publiés ou non, émanant des établissements d'enseignement et de recherche français ou étrangers, des laboratoires publics ou privés.

\section{(c)(1)}

Distributed under a Creative Commons Attribution| 4.0 International License 


\title{
Towards Continuous Collaboration on Civic Tech Projects: Use Cases of a Goal Sharing System Based on Linked Open Data
}

\author{
Shun Shiramatsu ${ }^{1}$, Teemu Tossavainen ${ }^{1,2}$, Tadachika Ozono ${ }^{1}$, and Toramatsu \\ Shintani ${ }^{1}$ \\ ${ }^{1}$ Graduate School of Engineering, Nagoya Institute of Technology, Japan \\ \{siramatu,ozono, tora\}@nitech.ac.jp \\ ${ }^{2}$ School of Science, Aalto University, Finland \\ teemu.tossavainen@aalto.fi
}

\begin{abstract}
Civic hackathon is a participatory event for prototyping of innovative services through collaboration between citizens and engineers towards addressing social issues. Although continuous contributions are needed for improving the prototypes and for applying them to social issues, participants frequently stop contributions after the hackathon due to their day job. To address this problem, we applied our Web system, called GoalShare, which gathers linked open data (LOD) of hierarchical goals to address social issues, to civic hackathons held in the city of Nagoya in Japan. We compared goal structures between two situations. The results showed that goal structures input by team members themselves with enough instruction time were relatively detailed but varied widely among teams, and those input by a single GoalShare user with limited time remained at a simple overview level but had uniform level of detail. A more user-friendly interface usable without instruction is required for real-world situations.
\end{abstract}

Keywords: Linked open data, civic tech, hackathon, public collaboration, open innovation

\section{Introduction}

Coverage of local government services in Japan is at risk of shrinking due to ongoing social issues that threaten the sustainability of regional societies, e.g., the aging population, disaster risks, and dilapidated infrastructure. In this context, public collaboration between broad citizens, local government officers, local companies, experts, and engineers has become more important to address social issues. Actual instances have arisen of addressing social issues by utilizing open data and mobile applications [1] with smartphones, which are now widely used by citizens. Civic Tech refers to an activity for applying information technology to addressing social issues through collaboration between engineers, citizens, and local governments [2]. In Japan, the Civic Tech movement has been rapidly growing since around 2013. 
Collaboration between a wide range of citizens is needed for addressing social issues using a civic-tech approach because engineers alone cannot design solutions without background context and because stakeholder citizens alone cannot utilize information technology. For example, local community managers and local IT companies are desired to participate in civic tech projects. Public outreach of contextual information on project activities is indispensable for getting a broad range of citizens to participate. The outreach of visions and approaches to addressing social issues facilitates collaboration with newly-arrived participants.

We have been developing a Web application called GoalShare for sharing such contextual information about collaborative activities by using linked open data (LOD) consisting of social issues and their solutions as goal hierarchies [3, 4]. In this paper, we describe our application of GoalShare to civic hackathons organized by civic tech communities. A hackathon, a coined term consisting of "hack" and "marathon," refers to a participatory event for prototyping services or applications in a short period such as over the weekend or for several hours. Civic hachathon [5] is a type of hackathon that is for prototyping civic tech applications. Figure 1 shows the typical flow of civic hackathons. Because outcomes of a civic hackathon in a short period tend to be an early prototype, continuous development is needed for applying the outcome to addressing real-world social issues. However, initial members frequently drop out of their project after a hackathon event due to the busyness of their day job. Contextual information on project activities needs to be disclosed and new participants need to be found to continue a project for improving the prototype as an outcome of a hackathon. Data on progress management and information sharing between project members should be reused for disclosing such contextual information to the public.

We applied GoalShare to two civic hackathons held in Nagoya city in Japan. This paper presents our qualitative analysis of difference in goal hierarchy data between a case of inputting by members of hackathon teams and a case of inputting by an audience who listens to the final presentation of hackathon teams.

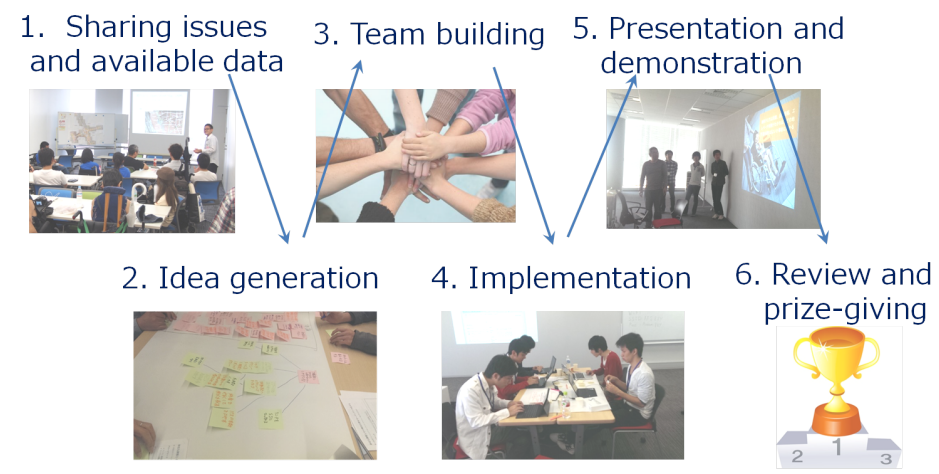

Fig. 1. Typical flow of civic hackathon 
We seek improvement in GoalShare for collaborating on Civic Tech projects. Concretely, we consider a function for a tagging skill set to goal data and person data for matching a goal and a person.

\section{Context of This Study}

\subsection{Civic Tech Organizations in Japan}

Code for Japan ${ }^{1}$, which is inspired by Code for America $^{2}$, was launched in 2013 [6]. Code for Japan collaborates with local organizations called "brigades" around the country. As of March 2015, 28 official brigades of Code for Japan have been registered. In this study, as we will describe later, GoalShare is used in civic hackathons organized by Code for Nagoya ${ }^{3}$, which is one of the official brigades of Code for Japan. The Open Knowledge Foundation Japan ${ }^{4}$ and Open Street Map Foundation Japan ${ }^{5}$ are also active in Civic Tech in Japan.

On March 2015, Civic Tech Forum $2015{ }^{6}$ was held in Tokyo, and over 300 people participated. The invited speakers of the forum were from the brigades of Code for Japan, research institutes, local non-profit organizations, and local companies that are related to Civic Tech.

\subsection{Systems for Sharing Issues and Ideas}

Civic Tech Issue Finder ${ }^{7}$ is a system for sharing civic tech issues and for supporting collaboration provided by Code for America. Issues in this service are stored as GitHub Issues with the tag "Help Wanted." GitHub ${ }^{8}$ is a widely used Web repository for source code.

Knowledge Connector ${ }^{9}$ provided by the Ministry of Economy, Trade and Industry of Japan and LinkData [7] is a Web platform for supporting commercialization of ideas that utilize open data [8]. It has a functionality for structuring events, organizations, ideas, datasets, issues, and subsidy programs.

Code for Kobe ${ }^{10}$ and Code for Japan are also planning to develop a Web system consisting of a "person finder" and "project finder" for Civic Tech activities in Japan.

Although the focus of this paper is close to the purpose of these systems, the originality of GoalShare is goal hierarchies as scenarios for addressing issues

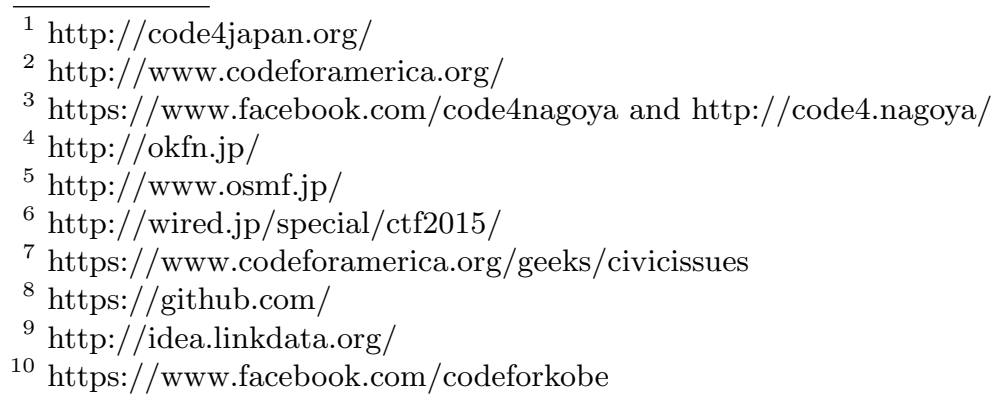


linked with existing SNSs and geographical datasets based on the LOD framework. The interoperability of the LOD framework can provide the possibility to link the dataset of GoalShare with those of the aforementioned systems in the future.

\subsection{Our Previous Study: Data Model of Goal Hierarchy}

We have developed a Web application called GoalShare ${ }^{11}$, which has a backend dataset based on the data model shown in Figure 2. The class socia:Issue represents the social issue, and socia:Goal represents the public goal as the solution of issues in this figure. The prefix "socia," which corresponds to the namespace http://data.open-opinion.org/socia-ns\#, is prepared for the data model that we designed. This data model is designed to satisfy the following requirements.

Context of agents: Represented by the link to people or organizations, e.g., those who wish for the goal or who participate in it. URIs of existing social networking services (SNSs), such as Facebook and Twitter, are used for linking to agents.

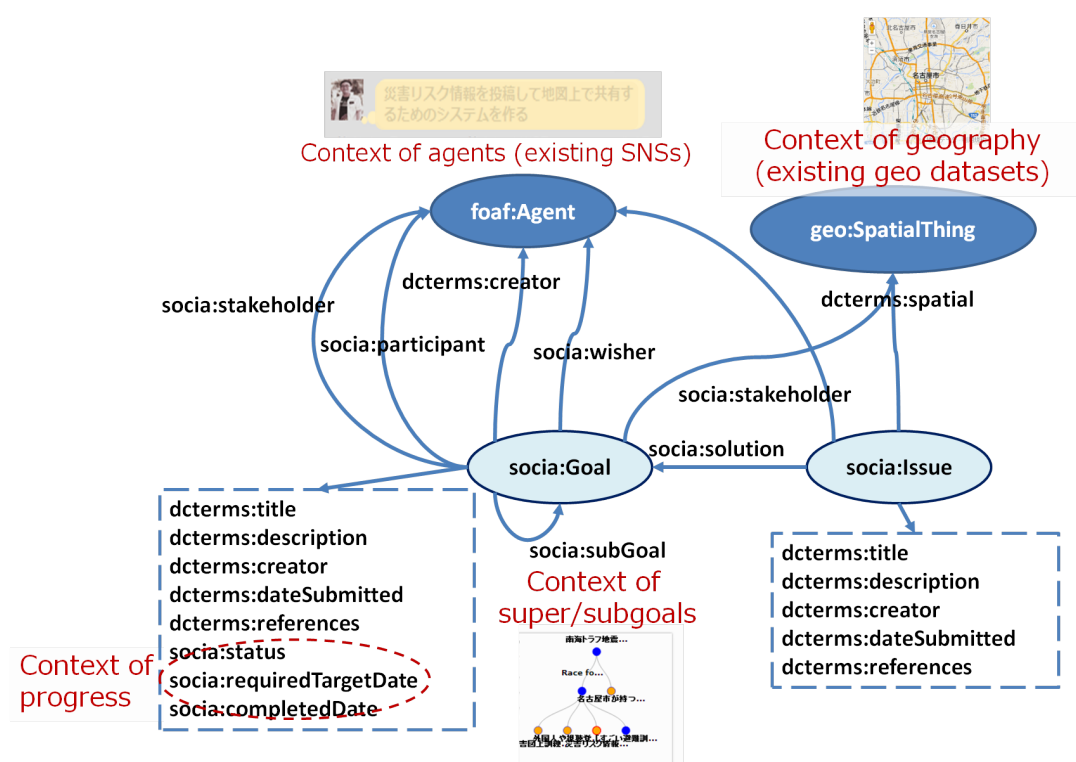

Fig. 2. Data model for public goal hirarchies as solutions of social issues

$\overline{{ }^{11} \text { http://radish.ics.nitech.ac.jp/goalshare/ }}$ 
Context of geography: Represented by the link to geographical regions. URIs of existing geographical datasets, such as GeoNLP LOD ${ }^{12}$ and GeoNames.jp ${ }^{13}$, are used for linking to geographical regions.

Context of super/subgoals: Represented by the goal hierarchy consisting of the link to subgoals. Concrete subgoals close to actions are linked with abstract final goals.

Context of progress: Represented by the properties for the deadline date and current status.

The context of super/subgoals was represented by the property socia:subGoal enabling users to organize a goal hierarchy and to break down each goal into subgoals close to concrete actions. Concrete subgoals also enable citizens to consider which subgoal they can participate in or contribute to. Moreover, when concrete subgoals are not agreed on by multiple participants even if a final abstract goal is generally agreed on by them, visualizing their goal hierarchies has the potential to support building a consensus about their differences and to compromise on their collaboration. Furthermore, the properties socia:status and socia:completedDate for the context of progress enable users seamless reuse of data across managing progress and sharing the current status of the project with new participants or potential collaborators because the values of socia:status ("NotStarted," "InProgress," "Aborted," and "Completed") represented by colors of goal nodes can support grasping which subgoals are currently in progress, which ones are not started yet, and which ones are already completed. These features enable new participants to grasp a current context of projects easily.

\section{Facilitating Collaboration on Civic Tech Project}

There are two types of participation in Civic Tech: one is voluntary participation such as with aforementioned brigade organizations, and the other is participation with fellowship programs. The voluntary participants, in particular, sometimes drop out of their project due to the busyness of their day job. For continuous progress of civic tech projects based on voluntary participation, we need to open a gate for new participants with the transparency of contextual information about "what the project members are trying to do" and "which subgoals the new participant can contribute to." Such transparency enables new project members to make a match between themselves and partial subgoals of the project.

Here, we deal with the possibility of match making between new participant $a$ and a concrete goal $g$, where $g$ is a partial subgoal of an abstract supergoal $g_{0}$. In this situation, $a$ and $g$ could collaborate when they satisfy one or more of the following conditions.

(a) Similarity of goals Goals or issues focused on by agent $a$ are similar to goal $g$.

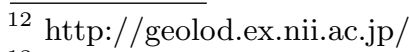

13 http://geonames.jp/ 
(b) Complementarity of resources Agent $a$ can provide resources (including skills as human resources) required to archive $g$.

In this study, we developed a function for matching $a$ and $g$ based on (a) the similarity of goals [3]. Many prototypes implemented in civic hackathons could have slept without brushing up because many civic hackathons have been held since around 2013 in Japan. If such a situation is true, the matchmaking function based on (a) can enable hackathon participants to reorganize their team for continuous acitivity. Moreover, we need to consider the matchmaking function based on (b) the complementarity of resources that was not dealt with in this study. In particular, we will consider the complementarity of skill sets for civic tech in a later section.

\section{Trial Use in Civic Hackathons}

We tried to apply the GoalShare to two actual civic hackathons; the Hackathon on Barrier-free Underground Mall at Nagoya Station ${ }^{14}$ held at October 2014 and the Hackathon on International Open Data Day 2015 in Nagoya ${ }^{15}$. These hackathons were organized by the Code for Nagoya and the non-profit organization Lisra. Hereafter, the former one is called the barrier-free hackathon, and the latter one is called the ODD hackathon. The barrier-free hackathon was held on both days of a weekend. The goal hierarchies were input in a debate between

Table 1. Differences in situations between two hackathons

\begin{tabular}{|l||l|l|}
\hline Hackathon & Barrier-free hackathon & ODD hackathon \\
\hline \hline Event period & Two days & One day \\
\hline $\begin{array}{l}\text { Time for instructing } \\
\text { usage }\end{array}$ & About 15 minutes & Cannot be ensured (0 minutes) \\
\hline Inputter & Team members themselves & $\begin{array}{l}\text { A single participant trained in } \\
\text { the usage of the GoalShare }\end{array}$ \\
\hline $\begin{array}{l}\text { Way to structure } \\
\text { goal hierarchies }\end{array}$ & $\begin{array}{l}\text { Structuring collaboratively be- } \\
\text { tween team members using } \\
\text { sticky notes before inputting } \\
\text { data to GoalShare }\end{array}$ & $\begin{array}{l}\text { Structuring by a single inputter } \\
\text { only with the GoalShare during } \\
\text { fentation for each team } \\
\text { sentes of an outcome pre }\end{array}$ \\
\hline $\begin{array}{l}\text { Time for structuring } \\
\text { goal hierarchies }\end{array}$ & About 45 minutes & $\begin{array}{l}5 \text { minutes (except for a team } \\
\text { participated in by the inputter) }\end{array}$ \\
\hline $\begin{array}{l}\text { Level of detail of goal } \\
\text { hierarchies }\end{array}$ & $\begin{array}{l}\text { Relatively detailed but vary } \\
\text { idely among teams }\end{array}$ & $\begin{array}{l}\text { Simple overview level but uni- } \\
\text { form level of detail (expect for } \\
\text { the inputter's team) }\end{array}$ \\
\hline $\begin{array}{l}\text { Maximum and min- } \\
\text { imum count of goal } \\
\text { nodes for each team }\end{array}$ & Max: 13, Min: 1 & $\begin{array}{l}\text { Max: 4, Min: 2 (expect for the } \\
\text { inputter's team) }\end{array}$ \\
\hline
\end{tabular}

$\overline{14}$ http://nagoya-bfree-hackathon.peatix.com/ (in Japanese)

15 http://opendata-nagoya2015.peatix.com/ (in Japanese) 
members of each participating team themselves. On the other hand, the ODD hackathon was held on just one day. The goal hierarchies were input by a member of the audience for the final presentation of each team. These situations are summarized in Table 1.

Figures 4 and 5 show goal hierarchies accumulated in each hackathon. The blue nodes represent ongoing goals, and the orange ones represent not-yet-started goals. Both of the goal hierarchies have top goals that correspond to a given theme of the hackathons and the direct subgoals of the top goals that correspond to the final goals of participating teams in the hackathons.

\subsection{Case of barrier-free hackathon}

In the barrier-free hackathon, members of four participating teams input goal hierarchy data of each team by themselves. After idea generation and team building, team members first wrote their goals for development on sticky notes and organized them into a hierarchy on a paper. Figure 3 shows examples of goal hierarchies created through debate between team members participating in the barrier-free hackathon. After creating the goal hierarchies consisting of sticky notes, they input the data into GoalShare. With consideration for ensuring time for development, an organizer of the barrier-free hackathon announced that subgoals after the fourth layers of the goal hierarchies on a paper could be omitted when inputting the subgoals into GoalShare.

As shown in Figure 4, the minimum count of goal nodes for each team was one, and the maximum count was thirteen. Although this difference was affected by the context thats the team inputting minimum nodes consisted of foreign students and that the instruction about GoalShare was spoken in Japanese, this result indicates that data input by hackathon participants themselves tended not to be uniform in quality.
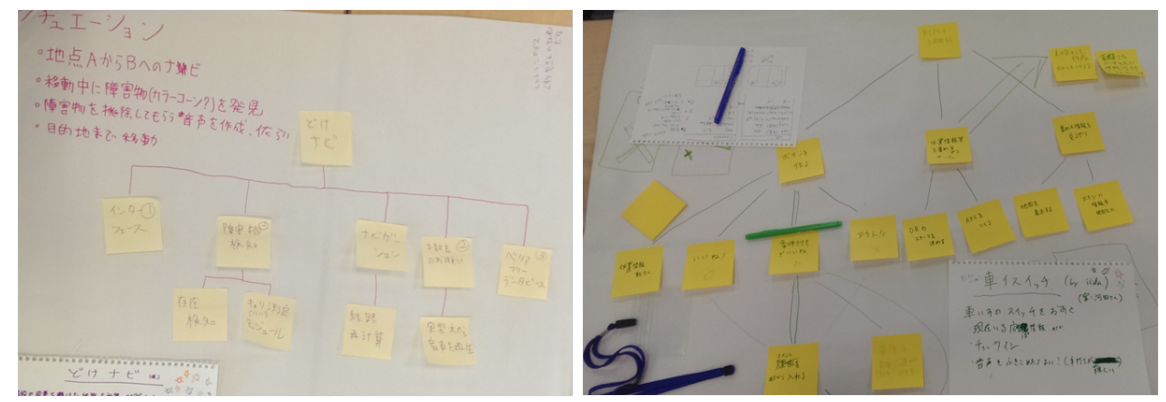

Fig. 3. Goal hierarchies written and structured by participants in the barrier-free hackathon 


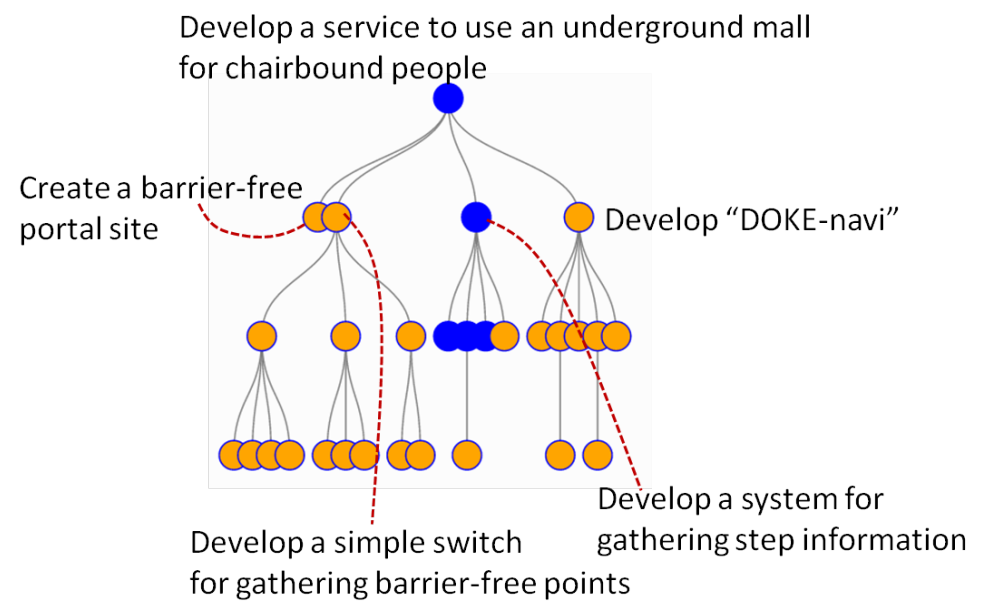

Fig. 4. Goal hierarchy gathered in barrier-free hackathon (translated from Japanese)

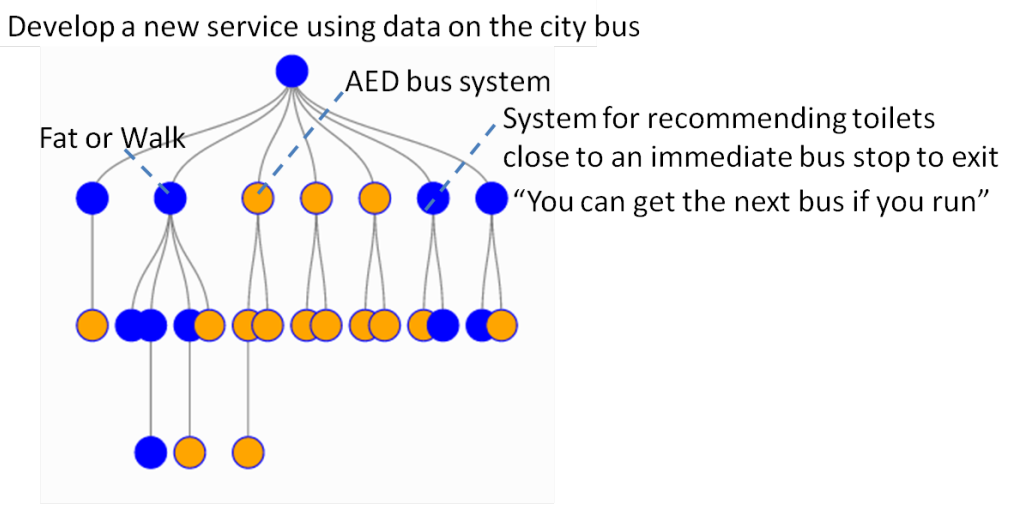

Fig. 5. Goal hierarchy gathered in ODD hackathon (translated from Japanese)

\subsection{Case of Open Data Day hackathon}

In the ODD hackathon, the time for instruction of GoalShare and for inputting of goal hierarchies was not provided to avoid reducing time for implementation. The reason was that the available time was less in the ODD hackathon than that in the barrier-free hackathon. As an alternative, one of the audience members for the final presentation given by seven participating teams input the goal hierarchies of each team. This goal inputter was proficient in the use of GoalShare.

The number of goal nodes for each team was about three or four because the presentation time for each team was short (about five minutes), with the exception of a team "Fat or Walk" in which the goal inputter participated. It is because the goal hierarchy of "Fat or Walk," the exceptional team, was cre- 
ated before the final presentation. Although the goal hierarchies of the other six teams were commonly abstract and their socia:wisher properties tended to be anonymous, such outline information can be used for considering the participation in the project by new candidate participants. Moreover, the blue nodes, which represent the ongoing subgoal with the property socia:state, in the ODD hackathon were more numerous than those in the barrier-free hackathon. This result indicates that data gathering from the final presentation of the hackathon by a proficient user can be the second best solution in cases where hackathon events cannot provide time for discussion and planning.

\section{Discussion: Towards application to real-world situations}

The aforementioned cases of trial use of the GoalShare indicate that a more user-friendly interface usable without instruction time is desired for real-world operations because organizing multiple days such a civic hackathon event is generally difficult. Because the main purpose of the civic hackathon is generally prototyping of an innovative service for social issues, the time for sharing goals should not interfere with the time needed for development more than necessary. We are currently implementing a more intuitive user interface, shown in Figure 6. This interface is designed using the metaphor of sticky notes, which is familiar to citizen participants in public workshops. This design of the user interface also considers remote and realtime co-authoring being implemented using the Google Hangout API.

Alternatively, a hybrid approach to inputting goal data through an interaction between team members and a proficient user in structuring goal hierarchies

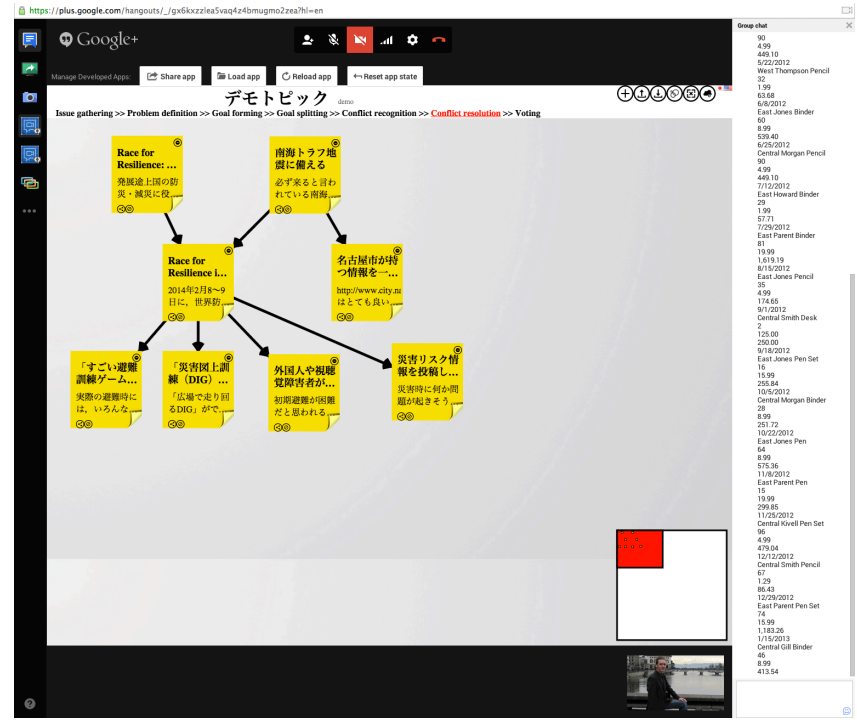

Fig. 6. The user interface designed using the metaphor of sticky notes 
after the presentation time can be considered for improving data quality. Although goal hierarchies input only by team members themselves are not uniform, the process for structuring goals by themselves is valuable for sharing detailed scenarios for addressing social issues. To attract new collaborators into a team after an event, concrete subgoal trees as a scenario to address a socia issue should be shared with potential collaborators. An interaction between team members and a proficient user in structuring goal hierarchies can improve the quality of goal hierarchies, and it does not disrupt development if the interaction is conducted after the final presentation. Moreover, a function for generating summary text of a goal hierarchy is desired to be provided to enable potential collaborators to understand the team's approach.

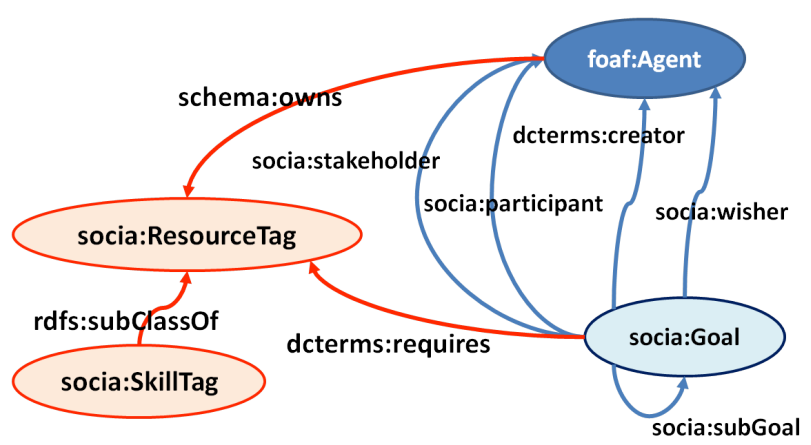

Fig. 7. Extension of data model to deal with skill set as human resources

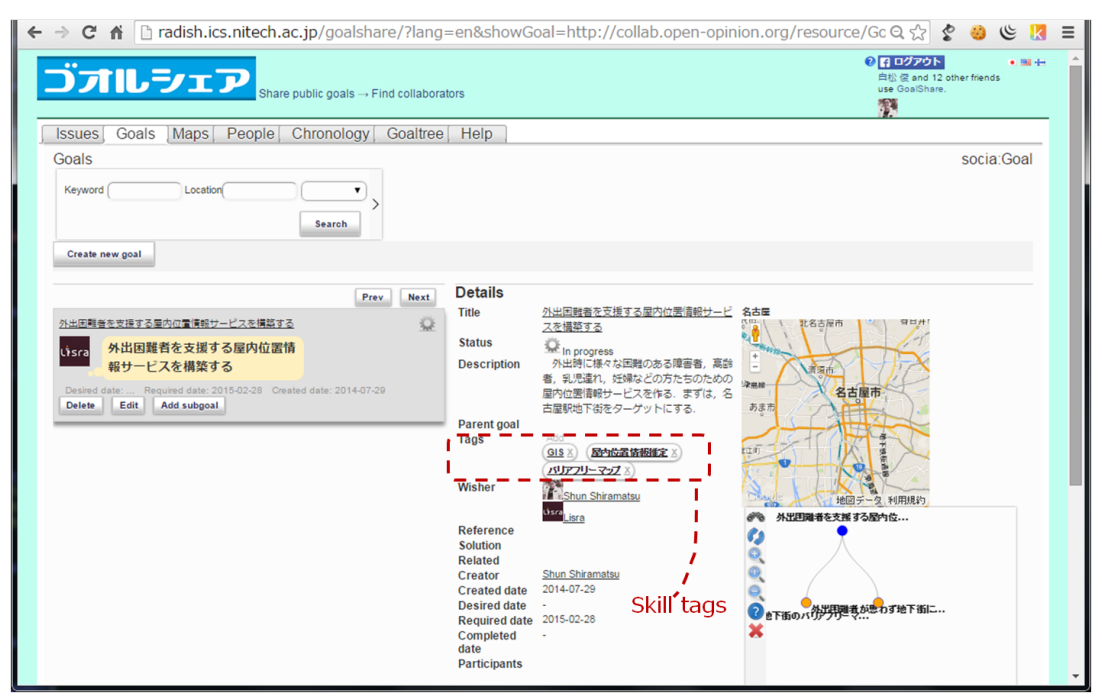

Fig. 8. Web interface of GoalShare extended to append skill tags 
Table 2. Examples of skill tag

\begin{tabular}{|c|l|}
\hline \multicolumn{1}{|c|}{ Tag } & Super concept \\
\hline \hline Android programming & Programming \\
\hline GIS & Programming \\
\hline Google Maps & GIS \\
\hline Open Street Map & GIS \\
\hline Sensor & Android Programming \\
\hline Acceleration sensor & Sensor \\
\hline Geomagnetic sensor & Sensor \\
\hline
\end{tabular}

Furthermore, recruiting new participants in the team building process (including after a hackathon event) needs complementarity of resources, e.g. a dataset or skill set, although we used GoalShare only just after team building in the aforementioned hackathon. We need to extend the data model shown in Figure 2 to enable us to describe a skill set as human resources. Figure 7 shows an extension of the properties connected to socia:Goal class and foaf:Agent class. The class socia:SkillTag represents the skill, and its super class socia:ResourceTag represents the general resource. The property determs:requires ${ }^{16}$ connects with socia:Goal, and the aforementioned classes correponding to resources. Resources or skills owned by agents are represented by the property schema:owns ${ }^{17}$.

Figure 8 shows our extended Web interface of GoalShare to enable users to add skill tags to each goal node, and Table 2 shows an example of the inheritance relationship between skills. Such interface and data structure can be used for matchmaking algorithms if a skill ontology can be prepared. Therefore, we need to consider how to build a skill ontology. For example, we will consider a subgraph extraction from general-purpose ontologies such as DBpedia ${ }^{18}$ to build a skill ontology.

\section{Conclusion}

We presented four requirements for designing a linked data model of goal hierarchies to facilitate collaboration in Civic Tech projects. We applied GoalShare to two actual civic hackathons held in Nagoya in Japan and qualitatively analyzed the differences in goal hierarchies between a case of inputting by members of hackathon teams and a case of inputting by an audience that listens to the final presentation of hackathon teams. These cases indicate that a more user-friendly interface usable without instruction time is desired for real-world situations. We presented a prototype of a more intuitive user interface designed using the metaphor of sticky notes, which are familiar to citizen participants in public workshops. Alternatively, to improve data quality, we considered a hybrid approach to inputting goal data through an interaction between team members

\footnotetext{
${ }^{16}$ http://purl.org/dc/terms/requires

17 http://schema.org/owns

18 http://dbpedia.org/
} 
and a proficient user in structuring goal hierarchies after the presentation time. Moreover, we considered an extension of our data model to deal with complementarity of skill sets that is important for Civic Tech, and we extended our Web interface for adding skill tags to each goal node.

In the future, we plan to integrate the similarity of goals and the complementarity of resources for improving the function to match citizens and Civic Tech projects. Moreover, we will apply a new intuitive user interface to goal input in the short final presentation of civic hackathons. The realtime co-authoring mechanism of the new user interface will be applied to an interaction between team members and a proficient user in structuring goal hierarchies after the presentation time.

Acknowledgments. This work was partially supported by a Grant-in-Aid for Young Scientists (B) (No. 25870321) from JSPS and a grant by the Nippon Foundation. We greatly appreciate the support by Prof. Nobuo Kawaguchi, Mr. Shinji Ichien, Mr. Takemi Nohara, partcipants in the hackathons, members of the NPO Lisra, and members of the Code for Nagoya.

\section{References}

1. Sandoval-Almazan, R., Gil-Garcia, J.R., Luna-Reyes, L.F., Luna, D.E., RojasRomero, Y.: Open government 2.0: Citizen empowerment through open data, web and mobile apps. In: Proceedings of the 6th International Conference on Theory and Practice of Electronic Governance. (2012) 30-33

2. Pyrozhenko, V.: Implementing open government: Exploring the ideological links between open government and the free and open source software movement. In: The 11th Annual Public Management Research Conference. (2011)

3. Shiramatsu, S., Tossavainen, T., Ozono, T., Shintani, T.: A Goal Matching Service for Facilitating Public Collaboration Using Linked Open Data. In: Electronic Participation. Proceedings of the 6th IFIP WG 8.5 International Conference, ePart 2014. Volume 8654 of Lecture Notes in Computer Science., Springer (2014) 114-127

4. Tossavainen, T., Shiramatsu, S., Ozono, T., Shintani, T.: Implementing a system enabling open innovation by sharing public goals based on linked open data. In: Proceedings of the 27th International Conference on Industrial, Engineering and Other Applications of Applied Intelligent Systems, Part II. Volume 8482 of Lecture Notes in Artificial Intelligence., Springer (2014) 98-102

5. Johnson, P., Robinson, P.: Civic Hackathons: Innovation, Procurement, or Civic Engagement? Review of Policy Research 31(4) (2014) 349-357

6. Takagi, S.: Research note: An introduction to the economic analysis of open data. The Review of Socionetwork Strategies 8(2) (2014) 119-128

7. Shimoyama, S., Gifford, D., Yoshida, Y., Toyoda, T.: Linkdata.org synergistically associating rdf data repository and application repository stimulates positive feedback of mutual developing data applications. In: The 2nd Joint International Semantic Technology Conference, JIST 2012 Nara, Japan, December 2012 Poster and Demonstration Proceedings. (2012) 19-20

8. METI: Supporting business creation with utilizing open data: Launch of "knowledge connector ( $\beta$ version)". http://www.meti.go.jp/press/2014/11/20141107002/ 20141107002.html (2014) (in Japanese). 